\title{
The Reliability of the Pediatric Functional Muscle Testing in Children with Developmental Delay
}

Hye-Jung Seo', Joong-Hwi Kim²

'Department of Physical Therapy, General Graduate School, Catholic University of Daegu, Gyeongsan; ${ }^{2}$ Department of Physical Therapy, College of Medicine Science, Catholic University of Daegu, Daegu, Korea

Purpose: The aim of this study was to examine the test-retest and inter-rater reliability of the pediatric functional muscle testing (PFMT) when applied to children with developmental delay.

Methods: Sixteen children with developmental delay (seven females, nine males) participated in this study. For the inter-rater reliability, each was scored on the PMFT by two pediatric physical therapists with more than 8 years of clinical experience on the same day. For assessment of the test-retest reliability, one therapist tested the children again within 10 days. The second measurement was performed by taking a first measurement in video. Intraclass correlation coefficient (ICC) was calculated to determine the test-retest and inter-rater reliability of the PFMT, and Chronbach's alpha was used to measure internal consistency.

Results: The results of this study were as follows: 1) The test-retest ICC of the score of the infant action month and the right side of the PFMT was from 0.53 to 1.00 and from 0.63 to 0.99 , respectively. 2) The inter-rater ICC of the score of the infant action month and the right side of the PFMT was from 0.66 to 1.00 and from 0.64 to 1.00 , respectively. 3) Chronbach's alpha was 0.93 . The internal consistency indicated excellent.

Conclusion: In conclusion, this study showed that the test-retest and inter-rater reliability of the PFMT was relatively high, except for a few items. Therefore, it can be suggested that the PFMT will be a useful tool for measurement of muscle strength for children with developmental delay if it be some modifications.

Keywords: Pediatric functional muscle testing, Reliability, Developmental delay

\section{서 론}

최근에 의학의 발달로 조산아 등의 고위험아와 외상성 뇌손상 아동 들의 생존율이 높아졌으며, ${ }^{1}$ 우리나라의 경우 저체중 출생아 및 극소 저체중출생아의 생존율이 1960년대에 33.8\%에서 2000년대에는 88.3\%까지 향상된 것으로 보고하였다. 이에 따라 발달장애의 위험을 가진 아동의 수도 증가하는 추세에 있다. 재태기간 25 주 이하의 미숙 아를 대상으로 교정연령 30 개월에 베일리 영아발달검사를 시행한 연 구에 의하면, 전체 생존아 중 $49 \%$ 에서 발달지연, 운동장애, 시각장애, 청각장애 등과 같은 신경발육 장애가 있었고, $23 \%$ 는 중증의 장애였 다고 보고하였다. 또한 출생체중 $750 \mathrm{~g}$ 미만이나 재태기간 25 주 미만 의 미숙아를 생후 $18-30$ 개월에 신경발달 검사를 시행한 결과 시각장 애, 청각장애, 뇌성마비와 같은 신경발달장애의 빈도가 약 30-50\%로 나타났다는 연구결과도 있다. 이러한 발달장애를 가진 아동의 기능
을 최대한 회복시키고 삶의 질을 향상시키기 위해서는 조기진단 및 조기치료가 중요하다.-8

그러나 발달지연을 호소하는 1 세 미만의 영아들을 정확하게 진단 하기는 매우 어렵고, ${ }^{9}$ 대부분의 소아물리치료사들도 치료 전, 후에 장애아동들을 객관적으로 평가하는 데 어려움을 느끼므로 진단 및 치료를 위하여 보다 정확하고 민감한 평가도구의 사용을 필요로 한 다.910 그러나, 장애아동의 전체적인 평가과정 중 평가도구를 사용하 는 부분은 일부에 지나지 않는다. ${ }^{9}$ 평가도구의 사용은 평가의 정확도 를 높여주고, 아동의 발달상태를 보호자에게 쉽게 설명할 수 있고, 치료 또는 수술적 처치 전후의 효과를 객관적으로 비교할 수 있으며, 평가결과를 연구의 기초자료로 활용할 수 있다는 이점이 있다." 이러 한 이유로 치료사들은 평가도구들을 사용하게 되는데, 이때 다양한 평가도구들 중 해당 아동에게 적절한 도구를 선별해야 한다. ${ }^{9}$

우리나라 건강보험에서 수가로 인정하는 물리치료와 관련된 평가
Received Jul 23, 2015 Revised Aug 14, 2015

Accepted Aug 18, 2015

Corresponding author Joong-Hwi Kim

E-mail ibobath@daum.net
Copylight (C) 2015 The Korea Society of Physical Therapy

This is an Open Access article distribute under the terms of the Creative Commons Attribution Non-commercial License (Http:// creativecommons.org/license/by-nc/3.0.) which permits unrestricted non-commercial use, distribution, and reproduction in any medium, provided the original work is properly cited. 
로는 크게 신경학적 기능검사와 외피, 근골 기능검사가 있으며, 신경 학적 기능검사에는 신경학적 검사와 신경학적 척도검사가 있으며, 외 피, 근골 기능검사에는 도수근력검사, 일상생활동작검사, 관절가동 범위검사, 등속성운동기능검사, 경직진자검사가 있다. ${ }^{12}$ 이 중 도수근 력검사는 모든 환자의 검사에 가장 기본이 되는 검사이며, 근력의 손 상정도를 평가하기 위해 가장 많이 사용되는 방법으로 골격계와 신 경계 손상정도의 평가를 위한 유용한 평가도구로 사용되어 왔다. ${ }^{13}$ 도수근력검사는 저항에 대한 장력을 발생시키는 근육의 능력을 측 정하기 위해 고안된 것으로, 검사의 신뢰도를 높이기 위해서는 환자 자세, 고정, 힘적용점, 그리고 환자의 동기와 같은 많은 요소들은 조절 되어야 하며, 검사 시작 전에 표준화된 지도방법으로 검사과정을 정 확하게 설명하여 환자의 이해도를 향상시키는 것이 중요하다..$^{14}$

이와 같은 이유로 인지력이나 주의력이 낮은 3-4세 이하의 아동에 서는 복잡한 지시나주의집중이 요구되는 근력검사 방법은 부적절하 다. 3 세 미만의 아이들은 도수근력검사, 소형역량계 혹은 등속검사와 같은 복잡한 검사 환경에 맞게 제대로 수행할 능력이 없기에 근력검 사는 기능활동의 관찰을 통한 기능근력검사를 이용하여 평가하는 것이 가장 좋다고 하였다. ${ }^{14}$ 그러나 1 세에서 5 세까지의 소아에게 적용 할 수 있는 공인된 정확한 근력검사방법은 없으며, ${ }^{14}$ 몇몇 연구자들이 영아와 유아의 근력검사를 위한 지침서를 제공하고 있으나, ${ }^{15,16}$ 신뢰 도와 타당도에 관한 연구는 아주 미비하다.

이에 본 연구에서는 3 세 미만의 아동이나 의사소통에 어려움이 있 는 아동에게도 적용 가능한 소아 도수근력검사의 개발 및 보급이 절 실히 요구된다고 사료되어, 국내에서는 2006년에 번역된 근력 및 감 각 검사라는 책의 6장에서 소개된 바 있는 Venita L.C.에 의해 개발된 소아 기능근력검사를 국내에 보급하기 위한 중요한 근거를 마련하기 위해 소아 기능근력검사에 대한 검사-재검사 및 측정자간 신뢰도를 알아보고자 한다. ${ }^{17}$

\section{연구 방법}

\section{1. 연구 대상}

본 연구는 2015년 5월부터 6월까지 경기도 소재 $\bigcirc \bigcirc$ 어린이의원에 서 외래 및 입원을 통해 재활치료를 받는 16 명을 대상으로 하였다. 대 상자 선정조건은 3 세 미만의 아동으로 신경학적 손상이 없는 단순 발달 지연으로 진단받은 아동으로, 정형외과적인 문제로 움직임에 문제가 있는 아동은 제외하였다.

\section{2. 실험 방법}

\section{1) 실험 절차}

본 연구의 선정기준에 적합한 대상아동의 부모에게 연구에 대한 설
명을 충분히 한 후 자발적 참여 동의서를 작성한 후에 시작되었다. 먼 저 대상아동들의 성별, 연령, 진단명 등 일반의학적인 특성을 수집하 였다.

소아 기능근력검사의 측정자 간 신뢰도를 알아보기 위하여 소아 물리치료 및 평가의 경험이 8 년 이상 되는 2 명의 치료사를 선정하여 검사에 대한 내용을 충분히 숙지하여 오염변인을 최소화하기 위해 서, 새로운 소아 기능근력검사를 습득할 있도록 3일 이상 훈련하였 다. ${ }^{16}$ 소아 기능근력검사의 검사-재검사 신뢰도를 조사하기 위해 각 대상자들을 평가하는 동시에 평가를 위한 과제를 수행하는 모습을 비디오로 촬영하였다. 그리고 검사와 재검사 사이의 기간은 최소한 7 일의 간격을 두어야 하고, 최대 14 일을 넘기지 않아야 학습과 발달상 의 변화에 따른 영향을 최소화시킬 수 있다는 선행연구 ${ }^{18}$ 와 같이 본 연구에서는 10 일 이내에 동일한 치료사가 대상자들이 과제를 수행 하는 모습이 촬영된 비디오를 보고 소아 기능근력검사로 재평가하 였다. ${ }^{19,20}$ 측정자 간 신뢰도는 마지막 검사에 2 명의 검사자가 동시에 평가하였다. ${ }^{21}$

\section{3. 측정 도구}

1) 소아 기능근력검사

소아 기능근력검사는 출생에서 5 세까지 아동들을 대상으로 각각의 근육과 근육군들의 근력을 평가하기 위해 고안되었다. 출생에서 생 후 6-7개월 사이의 아동은 발달반사를 시용하여 반응을 보았고, 생 후 6-7개월에서 1세까지의 아동은 중력을 고려하지 않고 자발적인 움 직임을 자극함으로써 그리고 1 세에서 5 세 사이의 아동은 중력에 대 한자발적 움직임을 자극함으로써 평가하도록 고안되었다.

소아 기능근력검사는 경부, 몸통, 상지 및 하지의 움직임으로 크게 4 가지 영역으로 구성되었으며, 각각의 움직임을 평가하기 위해 1 가지 이상의 특정자세에서 실시하도록 고안되었다. 또한 출생에서 생후 1 년 동안 성장 및 발달에 의해 수행할 수 있는 움직임들이 개월에 따 라 차이가 있으므로, 각 항목마다 개월을 체크하도록 고안되어 있어 각 움직임의 운동연령을 알 수 있다.

4 가지 영역 중 경부의 움직임은 경부신전, 경부전방굴곡, 경부외측 굴곡을 자세에 따라 4항목으로 구성되었으며, 몸통의 움직임은 몸통 굴곡, 몸통신전, 몸통회전을 자세에 따라 7항목, 상지의 움직임은 견 관절 굴곡, 팔꿉관절 신전을 자세에 따라 4항목, 하지의 움직임은 엉 덩관절과 무릎관절 굴곡 및 신전을 자세에 따라 5항목으로 총 20 항 목으로 구성되었다(appendix).

각 항목은 기존의 도수근력검사의 등급 척도와 같이 0-5등급으로 6등급으로 측정하도록 고안되었으나, 약간의 차이가 있다. 소아 기능 근력검사에서는 제시된 개월 수에 맞는 움직임이 수행이 가능하면 Fair (3등급), 움직임의 일부만 수행 가능하면 Poor (2등급), 움직임은 
Table 1. Test-retest reliability and inter-rater reliability of the pediatric functional muscle testing by intraclass correlation coefficients and confidence intervals

\begin{tabular}{|c|c|c|c|c|c|}
\hline \multirow{2}{*}{ Test item/Position } & & \multicolumn{2}{|c|}{ Test-retest $(n=16)$} & \multicolumn{2}{|c|}{ Inter-rater $(n=16)$} \\
\hline & & ICC & $95 \% \mathrm{Cl}$ & ICC & $95 \% \mathrm{Cl}$ \\
\hline \multirow[t]{2}{*}{ Neck Extension/Prone } & Month & 0.87 & $0.66-0.95$ & 0.66 & $0.23-0.87$ \\
\hline & Right side & 0.87 & $0.68-0.95$ & 0.87 & $0.68-0.95$ \\
\hline \multirow[t]{2}{*}{ Neck Extension/Horizontal suspension } & Month & 0.74 & $0.40-0.90$ & 0.85 & $0.63-0.95$ \\
\hline & Right side & 0.80 & $0.51-0.92$ & 0.94 & $0.83-0.98$ \\
\hline \multirow[t]{2}{*}{ Neck Flexion/Supine } & Month & 0.87 & $0.64-0.95$ & 0.78 & $0.47-0.92$ \\
\hline & Right side & 0.95 & $0.87-0.98$ & 0.91 & $0.76-0.97$ \\
\hline \multirow[t]{2}{*}{ Neck lateral Flexion/Vertical suspension } & Month & 0.53 & $0.06-0.81$ & 0.76 & $0.44-0.91$ \\
\hline & Right side & 0.88 & $0.69-0.96$ & 0.87 & $0.67-9.95$ \\
\hline \multirow[t]{2}{*}{ Trunk Flexion(upper)/Pulled-to-sit } & Month & 0.66 & $0.26-0.87$ & 0.75 & $0.41-0.90$ \\
\hline & Right side & 0.95 & $0.86-0.98$ & 0.84 & $0.61-0.94$ \\
\hline \multirow[t]{2}{*}{ Trunk Flexion(lower)/Supine } & Month & 0.80 & $0.51-0.92$ & 0.70 & $0.33-0.88$ \\
\hline & Right side & 0.88 & $0.70-0.96$ & 0.93 & $0.80-0.97$ \\
\hline \multirow[t]{2}{*}{ Trunk ExtensionProne } & Month & 1.00 & $1.00-1.00$ & 1.00 & $1.00-1.00$ \\
\hline & Right side & 0.79 & $0.50-0.92$ & 0.79 & $0.50-0.92$ \\
\hline \multirow[t]{2}{*}{ Trunk Flexion \& Extension/Sitting } & Month & 1.00 & $1.00-1.00$ & 0.85 & $0.62-0.95$ \\
\hline & Right side & 0.97 & $0.93-0.99$ & 0.79 & $0.49-0.92$ \\
\hline \multirow[t]{2}{*}{ Trunk Flexion \& Extension/Quadruped } & Month & 0.99 & $0.98-1.00$ & 0.82 & $0.55-0.93$ \\
\hline & Right side & 0.97 & $0.90-0.99$ & 0.79 & $0.50-0.92$ \\
\hline \multirow[t]{2}{*}{ Trunk Rotation/Supine } & Month & 0.95 & $0.87-0.98$ & 0.87 & $0.67-0.95$ \\
\hline & Right side & 0.73 & $0.37-0.89$ & 0.86 & $0.78-0.97$ \\
\hline \multirow[t]{2}{*}{ Trunk Rotation/Rotation into sitting } & Month & 1.00 & $1.00-1.00$ & 1.00 & $1.00-1.00$ \\
\hline & Right side & 0.99 & $0.97-0.99$ & 0.99 & $0.97-0.99$ \\
\hline \multirow[t]{2}{*}{ Shoulder Flexion/Supine } & Month & 0.88 & $0.69-0.96$ & 0.87 & $0.67-0.95$ \\
\hline & Right side & 0.89 & $0.71-0.96$ & 0.89 & $0.71-0.96$ \\
\hline \multirow[t]{2}{*}{ Shoulder Flexion/Sitting } & Month & 1.00 & $1.00-1.00$ & 1.00 & $1.00-1.00$ \\
\hline & Right side & 0.98 & $0.96-1.00$ & 1.00 & $1.00-1.00$ \\
\hline \multirow[t]{2}{*}{ Elbow Extension/Prone } & Month & 1.00 & $1.00-1.00$ & 0.67 & $0.28-0.87$ \\
\hline & Right side & 0.78 & $0.47-0.92$ & 0.73 & $0.38-0.90$ \\
\hline \multirow[t]{2}{*}{ Elbow Extension/Sitting (Parachute R.) } & Month & 1.00 & $1.00-1.00$ & 1.00 & $1.00-1.00$ \\
\hline & Right side & 0.98 & $0.93-0.99$ & 0.96 & $0.88-0.99$ \\
\hline \multirow[t]{2}{*}{ Hip \& Knee Flexion/Supine } & Month & 0.95 & $0.85-0.98$ & 0.90 & $0.74-0.96$ \\
\hline & Right side & 0.81 & $0.54-0.93$ & 0.76 & $0.43-0.91$ \\
\hline \multirow[t]{2}{*}{ Hip \& Knee Flexion/Prone } & Month & 0.97 & $0.91-0.99$ & 0.94 & $0.85-0.98$ \\
\hline & Right side & 0.63 & $0.20-0.85$ & 0.64 & $0.22-0.92$ \\
\hline \multirow[t]{2}{*}{ Hip \& Knee Extension/Prone } & Month & 0.94 & $0.83-0.98$ & 0.94 & $0.83-0.98$ \\
\hline & Right side & 0.84 & $0.61-0.94$ & 0.84 & $0.61-0.94$ \\
\hline \multirow[t]{2}{*}{ Hip \& Knee Extension/Standing } & Month & 1.00 & $1.00-1.00$ & 1.00 & $1.00-1.00$ \\
\hline & Right side & 1.00 & $1.00-1.00$ & 1.00 & $1.00-1.00$ \\
\hline \multirow[t]{2}{*}{ Hip \& Knee Extension/Independent standing } & Month & 0.99 & $0.97-1.00$ & 0.99 & $0.97-1.00$ \\
\hline & Right side & 0.82 & $0.55-0.93$ & 0.85 & $0.61-0.94$ \\
\hline
\end{tabular}

ICC, Intraclass correlation coefficients; Cl, Confidence intervals.

일어나지 않지만 움직임을 시도할 때 근수축의 촉진이 가능하면 Trace (1등급), 그렇지 않으면 Zero (0등급), Good (4등급)과 Normal (5 등급)은 저항 정도의 강약에 의해 평가되어진다.

\section{4. 분석 방법}

모든 통계자료의 처리에는 SPSS version 19.0 을 사용하였으며, 통계학 적 유의수준 $(\alpha)$ 을 0.05 이하로 하여 검정하였다. 대상자들의 일반적인 특성은 빈도분석을 하였고, 검사-재검사, 측정자 간 신뢰도는 급간내 
상관계수(intraclass correlation coefficients, ICCs)를 이용하였다. 본 연 구에서 신뢰도 수준은 이전의 연구를 바탕으로 ICC가 0.75 이상이면 매우 신뢰할 수준으로 간주하였다. ${ }^{22}$ 내적일치도를 알아보기 위하여 크론바알파(Cronbach's alpha)는 첫번째 검사자 평가지의 결과를 이 용하였다. ${ }^{24}$ 본 연구의 대상아동이 비교적 좌우 차이가 심하지 않은 발달지연 아동이었으며, 좌우 근력등급의 차이가 없는 것으로 나타 나 오른쪽근력평가 값을 사용하여 분석하였다.

\section{연구 결과}

\section{1. 연구대상자의 일반적 특성}

본 연구에 참여한 발달지연 아동의 일반적 특성을 살펴보면, 남자가 9명, 여자가 7명이었으며, 연령은 9개월에서 32 개월 아동으로 평균연 령은 19.31 개월이었으며, 표준편차는 7.40 개월이었다. 이 중 12 개월 미 만 아동은 4 명, 12 개월에서 24 개월 미만 아동은 7 명, 24 개월에서 36 개 월 미만 아동은 5 명으로 분포하였다. 아동의 운동기능수준은 독립 적 보행이 가능한 아동 1 명, 독립적 서기 1 명, 독립적 앉기 5 명, 구르기 가능한 아동은 4 명이었다. 나머지 5 명의 아동은 독립적으로 이동이 불가능한 아동이었다.

\section{2. 검사-재검사 신뢰도}

소아 기능근력검사의 검사-재검사 신뢰도 수준은 개월평가에서는 0.53 에서 1.00 으로 다양하게 나타났으며, 오른쪽 근력평가에서는 0.63 에서 0.99 로 다양하게 나타났다.

영역별 세부항목을 살펴보면 경부의 움직임에서는 개월평가에서 경부신전의 수평위로 들어올린 자세와 경부외측굴곡에서 각각 0.74 , 0.53 으로 낮은 신뢰도를 보였으나, 나머지 2 개 항목에서는 높은 신뢰 도를 보였다. 오른쪽 근력 평가에서는 높은 신뢰도를 보였다. 몸통의 움직임에서는 개월 평가에서는 상부몸통 굴곡에서 0.66 으로 낮은 신 뢰도를 보였으나 나머지 항목에서는 높은 신뢰도를 보였다. 오른쪽 근력평가에서는 몸통 회전에서 0.73 으로 보통의 신뢰도를 보였으나 나머지 항목에서는 높은 신뢰도를 보였다. 상지의 움직임에서는 개월 평가 및 오른쪽 근력평가에서 모두 높은 신뢰도를 보였다. 하지의 움 직임에서는 개월평가에서는 모든 항목에서 매우 높은 신뢰도를 보였 으나, 오른쪽 근력평가에서 엎드린 자세에서의 엉덩관절 및 무릎관 절 굴곡에서 0.64 로 낮은 신뢰도를 보였으나 나머지 항목에서는 높은 신뢰도를 보였다(Table 1).

\section{3. 측정자 간 신뢰도}

소아 기능근력검사의 측정자 간 신뢰도 수준은 개월평가에서는 0.66 에서 1.00 으로 다양하게 나타났으며, 오른쪽 근력평가에서는 0.64 에
서 1.00 으로 다양하게 나타났다.

영역별 세부 항목을 살펴보면, 경부의 움직임에서는 개월평가에서 엎드린 자세의 경부신전에서 0.66 으로 낮은 신뢰도를 보였으나, 나머 지 항목에서는 비교적 높은 신뢰도를 보였다. 오른쪽 근력평가에서 는 모든 항목에서 높은 신뢰도를 보였다. 몸통의 움직임에서는 개월 평가에서 하부몸통 굴곡에서 0.70 으로 보통의 신뢰도를 보였으나, 나 머지 항목에서는 높은 신뢰도를 보였다. 오른쪽 근력평가에서는 모 두 높은 신뢰도를 보였다. 상지의 움직임에서는 개월평가에서 팔꿉 관절 신전에서 0.67 로 낮은 신뢰도를 보였으나, 나머지 항목에서는 모 두 높은 신뢰도를 보였다. 오른쪽 근력평가에서 팔꿉관절 신전 항목 에서 0.73 으로 낮은 신뢰도를 보였으나, 나머지 항목에서 모두 높은 신뢰도를 보였다. 하지의 움직임에서는 개월평가에서는 모든 항목에 서 매우 높은 신뢰도를 보였으나, 오른쪽 근력평가에서 엎드린 자세 에서의 엉덩관절 및 무릎관절 굴곡에서 0.63 으로 낮은 신뢰도를 보였 으나 나머지 항목에서는 높은 신뢰도를 보였다(Table 1).

\section{4. 내적 일치도}

내적 일치도는 크론바 알파값이 0.93 으로 매우 높게 나타났다.

\section{고 찰}

물리치료사가 운동장애를 가진 아동에게 효과적인 치료를 제공하 기 위해서는 아동이 가진 문제점들을 파악하기 위한 정확한 평가과 정이 선행되어야 한다. ${ }^{24,25}$ 그 중에서도 물리치료사가 신경학적 손상 을 가진 환자들을 임상적으로 평가하기 위해서는 도수근력검사가 빈 번하게 사용되고 있다. ${ }^{26,27}$ 그러나 아동에게 적합한 도수근력검사는 여러 연구자들에 의해 소개는 되어지고 있으나, ${ }^{14}$ 신뢰도에 대한 연구 는 아주 미비하였다. 이에 본 연구에서는 3 세 미만의 발달지연 아동, 특히 의사소통이 원활하지 않는 아동을 대상으로 Venita L.C.에 의해 개발된 소아 기능근력검사의 검사-재검사 및 측정자 간의 신뢰도와 내적 일치도를 알아보았다.

첫 번째로 소아 기능근력검사의 검사-재검사 신뢰도를 분석한 결 과, ICC의 범위가 개월평가에서는 0.53 에서 1.00 으로, 오른쪽 근력평 가에서는 0.63 에서 0.99 로 다양하게 나타났다. 개월평가는 각 움직임 을 시행할 때 나타나는 양상을 보고 해당 개월 수를 선택하도록 고안 되었는데, 0.75 이하의 항목은 총 20 개의 항목 중에 경부신전과 경부 외측굴곡 및 상부몸통굴곡의 3 개 항목으로 수행하는 움직임의 각도 를 기준으로 해당 개월을 선택하도록 되어 있어, 처음 평가의 비디오 촬영을 통해 재검사하는 과정에서 3 차원적인 관찰에 차이가 있어서 이러한 결과가 나타난 것으로 사료된다. ${ }^{21}$ 나머지 17 개의 항목은 0.80 에서 1.00 으로 아주 높은 신뢰도를 나타내었다. 오른쪽 근력평가에서 
는 바로 누운 자세에서 몸통회전 근력평가가 0.73 으로 보통의 신뢰도 를 보였으며, 나머지 18 개의 항목에서는 0.78 에서 1.00 으로 비교적 높 은 신뢰도를 보였다. 그러나 엎드린 자세에서 엉덩관절 및 무릎관절 굴곡 평가항목은 0.63 으로 낮은 신뢰도를 보였는데, 이 항목은 측정 자간 신뢰도에서도 0.64 로 낮은 신뢰도를 보였다. 이는 아동의 반응 에 대한 설명이 부족하여 평가자가 등급을 정하는 데 정확도가 감소 한 것으로 사료된다. 검사-재검사 신뢰도는 이 측정도구가 반복 측정 할 경우 안정성이 있는가에 대한 것으로, ${ }^{23}$ 본 연구에서 사용된 소아 기능근력검사가 실제 임상에서 사용하거나 연구의 도구로서 사용되 기 위해서는 몇 가지 사항에서 보정되어야 할 필요가 있을 것으로 사 료된다.

두 번째로 소아 기능근력검사의 측정자간 신뢰도를 분석할 결과, 개월평가에서는 0.66 에서 1.00 으로, 오른쪽 근력평가에서는 0.64 에서 1.00 으로 다양하게 나타났다. 개월평가에서는 엎드린 자세에서 경부 신전, 하부몸통 굴곡, 엎드린 자세에서 팔꿉관절 신전 항목에서 각 $0.66,0.70,0.67$ 로 낮은 신뢰도를 보였다. 이러한 결과로 세 가지 항목에 서 제시하고 있는 개월 간의 차이의 기준을 평가하는 데 두 명의 치 료사가 서로 차이가 있음을 알 수 있었다. 이를 개선하기 위해서는 좀 더 명확한 개월 간의 차이를 제시해 주는 것이 필요하다고 사료된다. 또한 아동의 연령이 매우 어리기 때문에 주변 환경이나 검사자와의 친숙 여부에 따라 움직임의 수행 정도에 차이가 있었을 것이라 사료 된다. 나머지 17 개 항목에서는 0.75 에서 1.00 으로 비교적 높은 신뢰도 를 보였다. 오른쪽 근력평가에서는 엎드린 자세에서 엉덩관절 및 무 릎관절 굴곡과 팔꿉관절 신전 항목을 제외한 나머지 18 개 항목에서 0.73 에서 1.00 으로 비교적 높은 신뢰도를 보였다.

마지막으로 내적 일치도에서 크론바 알파값이 0.93 으로 매우 높은 것으로 나타났다. 이를 통해 소아 기능 근력검사의 측정 항목 간에 동 일한 특성을 측정함을 증명하였다. ${ }^{23}$

본 연구의 결과를 통해 소아 기능근력검사의 몇 개의 항목을 제외 한 대부분의 세부항목에서 중등에서 높은 신뢰도가 있음을 확인할 수 있었다. 이것은 이전의 여러 연구자들이 1 세에서 5 세까지 아동은 다양한 방법으로 움직임들을 중력에 반하여 사용하기 때문에 5 세 이하의 소아에서 근육검사는 신뢰할만한 검사방법이 아닐 수도 있 다고 한 것17 같이 본 연구에서도 몇 개의 항목에서 낮은 신뢰도가 나 타난 것으로 사료된다.

그러나 아동의 근력을 평가하기 위한 도수근력검사의 신뢰도를 높 이기 위해 도수검사기구를 제안하고, 소형약력계를 이용하거나, 등 속성 기구를 사용할 것을 주장하는 이전 연구들 17,27 과 같이 본 연구 에서 사용한 소아 기능근력검사의 신뢰도를 높이기 위한 앞으로의 연구에서는 경사계 등 관절가동범위를 측정할 수 있는 도구와 함께 사용되고, 또한 각 근력 등급 및 개월 간의 차이에 대한 설명이 좀더
구체적으로 수정된다면, 보다 높은 검사-재검사 및 측정자 간 신뢰도 가 높아질 것이라사료된다.

본 연구에서는 운동장애가 있는 아동 중에 발달지연 아동 및 3 세 미만의 아동으로만 국한되어 있어서, 다양한 운동장애가 있는 아동, 특히 뇌성마비 등 신경계 이상으로 인해 비정상적인 긴장도가 나타 나는 아동과 3 세 이상의 아동들에게 일반화하여 적용하는 데 어려 움이 있다. 앞으로의 연구에서는 다양한 운동장애가 있는 아동에게 적용 가능한지에 대한 연구와 연령에 따른 차이가 있는지에 대한 후 속 연구들이 이루어져야 할 것이다.

결론적으로 본 연구에서 사용된 소아 기능적 도수근력검사는 발 달지연 아동뿐만 아니라 의사소통이 어려운 3 세 미만의 아동의 근력 을 평가하기 위해 검사방법의 몇 가지 수정과 관절 범위를 측정할 수 있는 도구를 함께 사용한다면, 임상에서 근력평가를 위한 유용한 평 가도구로 사용될 수 있을 것으로 사료된다.

\section{ACKNOWLEDGEMENTS}

본 연구는 2013학년도 대구가톨릭대학교 연구비지원에 의한 것임.

\section{REFERENCES}

1. Kurtz LA, Scull SA. Rehabilitation for developmental disabilities. Pediatr Clin North Am. 1993;40(3):629-42.

2. Bae YM, Bae CW. The changes in the mortality rates of low birth weight infant and very low birth weight infant in Korea over the past 40 years. J Korean Med Sci. 2004;19(1):27-31.

3. Allen MC. The high-risk infant. Pediatr Clin North Am. 1993;40(3):47989.

4. Wood NS, Marlow N, Costeloe K et al. Neurologic and developmental disability after extremely preterm birth. The New England Journal of Medicine. 2000;343(6):378-84.

5. Kim CR. The limit of viability and care of fetal infants. Korean Journal of Perinatology. 2004;15(4):341-9.

6. Park CI, Park ES, Shin JC et al. Early treatment effect in children with cerebral palsy and delayed development. Annals of Rehabilitation Medicine. 1999;23(6):1127-33.

7. Park SK. The early assessment of cerebral palsy. J Kor Phys Ther. 1993; 5(1):95-9.

8. Lim EH, Ju HO. Health-related quality of life in the early childhood of preterm children. 2015;21(1):37-45.

9. Park HJ, Yi CH, Cho SH et al. Physical therapist's understanding and the usage of assessment tools for children with delayed development and cerebral palsy. Phys Ther Korea. 2000;7(1):1-21.

10. Hallam P, Weindling AM, Klenka $\mathrm{H}$ et al. A comparison of three procedures to assess the motor ability of 12-month-old infants with cerebral palsy. Dev Med Child Neurol. 1993;35(7):602-7.

11. Tecklin JS. Pediatric Physical Therapy. J.B. Lippincott. 2008.

12. Tecklin JS. Pediatric Physical Therapy. J.B. $4^{\text {th }}$ ed, Philadelphia, Lippin- 
cott. 2008

13. Scott CC, George JG. On the reliability and validity of manual muscle testing: a literature review. Chiropractic \& Osteopathy. 2007;15(4):1-23.

14. Nancy BR. Muscle and Sensory Testing. 3rded. New York, Elsvier, 2012.

15. Turman JE, Van Vranken T. Testing of infants, toddlers, and preschool children. In: Hislop HJ, Montgomery J, eds. Daniels and Worthingham's Muscle Testing: Techniques of Manual Examination. Philadelphia: WB Sounders, 2002:253-88.

16. Escolar DM, Henricson EK, Mayhew J et al. Clinical evaluator reliability for quantitative and manual muscle testing measures of strength in children. Muscle \& Nerve. 2001;24:787-93.

17. Venita LC. Techniques of pediatric muscle testing. In: Nancy BR, ed, Muscle and Sensory Testing, 2nded, Seoul, Koonja, 2006:459-500.

18. Ko JY, Lim KW. Test-retest, inter-rater, and intra-rater reliability of a pediatric balance scale in children with cerebral palsy. J Kor Phys Ther. 2010;22(4):43-8.

19. An SH, Lee DG, Lee YB et al. Inter-rater-absolute reliability and concurrent validity of Tinetti-gait (Korean version) in stroke patients. J Korean Soc Phys Med. 2014;9(2):201-11.

20. Kim GW, Ko JY, Baek SG. The reliability of pediatric balance scale based on the rater's clinical work experience and test experience. J Kor Phys Ther. 2010;2(6):5-42.

21. An SH, Seo HD, Chung YJ. Reliability and validity the Korean version of the dynamic gait index in patients with stroke. J Spec Edu \& Rehab Sci. 2011;50(2):286-306.

22. Yoo SH, Ha HK, Lee HJ. Korean cultural adaptation of working alliance inventory and its reliability. J Kor Phys Ther. 2014;26(2):90-6.

23. Park JY, Cho SH. The reliability and validity of Korean version of the wheelchair user's shoulder pain index in wheelchair users. J Korean Soc Phys Med. 2013;8(4):573-82.

24. Ko MS, Lee NH, Lee JA et al. Inter-examiner reliability of Korean version of the pediatric balance scale. Phys Ther Korea. 2008;15(1):86-91.

25. Julaine MF, Shree P, Wendy MK et al. Intrarater reliability of manual muscle test (medical research council scale) grades in duchenne's muscular dystrophy. Phys Ther. 1992;72(2):115-22.

26. Hong WS, Lim GW. Assessment of isometric muscle strength of shoulder girdle: a reliability study. J Kor Phys Ther. 2007;19(6):17-22.

27. Yu CS, Chang SK. The isokinetic evaluation of knee extensor and flexors in the normal subjects for those twenties. J Kor Phys Ther. 2013;25(4): 167-73. 
Reliability of Pediatric Functional Testing in DD

Appendix. The sheet for the pediatric functional muscle testing

\begin{tabular}{|c|c|c|c|c|}
\hline Movements & Position & Month of Infant action & Right & Left \\
\hline \multirow[t]{2}{*}{ Neck Extension } & Prone & $\square 0-3 m \quad \square 4-6 m \quad \square 7-9 m$ & & \\
\hline & Horizontal suspension & $\square 0-3 m \quad \square 4-6 m$ & & \\
\hline Neck Flexion & Supine & $\square 0-3 m \quad \square 4-5 m \quad \square 6-7 m$ & & \\
\hline Neck lateral Flexion & Vertical suspension & $\square 0-3 \mathrm{~m} \quad \square 4 \mathrm{~m}$ & & \\
\hline Trunk Flexion (upper) & Pulled-to-sit & $\square 0-3 m \quad \square 4-6 m \quad \square 7-12 m$ & & \\
\hline Trunk Flexion (lower) & Supine & $\square 0-3 m \quad \square 4-6 m \quad \square 7-9 m$ & & \\
\hline Trunk Extension & Prone & $\square 4-6 m \quad \square 7-9 m$ & & \\
\hline \multirow[t]{2}{*}{ Trunk Flexion \& Extension } & Sitting & $\square 6 m \quad \square 7-9 m$ & & \\
\hline & Quadruped & $\square 6 m \quad \square 7-9 m$ & & \\
\hline \multirow[t]{2}{*}{ Trunk Rotation } & Supine & $\square 4 \mathrm{~m} \quad \square 5 \mathrm{~m} \quad \square 6 \mathrm{~m} \quad \square 8-9 \mathrm{~m}$ & & \\
\hline & Rotation into sitting & $\square 7-9 m$ & & \\
\hline \multirow[t]{2}{*}{ Shoulder Flexion } & Supine & $\square 6 \mathrm{~m}$ & & \\
\hline & Sitting & $\square 6 \mathrm{~m} \quad \square 11 \mathrm{~m}$ & & \\
\hline \multirow[t]{2}{*}{ Elbow Extension } & Prone & $\square 0-3 \mathrm{~m} \quad \square 6 \mathrm{~m}$ & & \\
\hline & Sitting (Parachute R.) & $\square 4 \mathrm{~m} \quad \square 7 \mathrm{~m} \quad \square 9-12 \mathrm{~m}$ & & \\
\hline \multirow[t]{4}{*}{ Hip \& Knee Flexion } & Supine & $\square 0-3 m \quad \square 4-6 m$ & & \\
\hline & & $\square 7-9 m \quad \square 12 m$ & & \\
\hline & Prone & $\square 0-3 m \quad \square 4-6 m \quad \square 7-10 m$ & & \\
\hline & & $\square 10-12 m \quad \square 12 m$ & & \\
\hline \multirow[t]{4}{*}{ Hip \& Knee Extension } & Prone & $\square 4-6 m \quad \square 7-9 m \quad \square 12 m$ & & \\
\hline & Standing & $\square 12 \mathrm{~m}$ & & \\
\hline & Independent standing & $\square 0-3 m \quad \square 4-5 m \quad \square 6 m$ & & \\
\hline & & $\square 9 \mathrm{~m} \quad \square 10 \mathrm{~m} \quad \square 12 \mathrm{~m}$ & & \\
\hline
\end{tabular}

